\title{
Mechanisms for inspiring action in South African youth
}

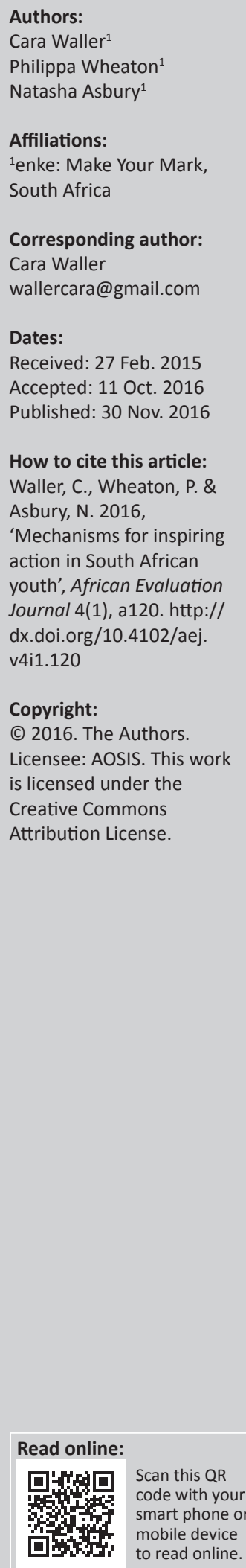

Background: Many young people in South Africa are in the process of actively changing their country. To positively contribute to the development agenda, young people need the skills and capacity to initiate and sustain change and set themselves apart as leaders.

Objectives: This article provides insight into multi-level mechanisms that allow young South Africans opportunities to grow personally and to take action on issues of concern to themselves and their communities.

Method: The enke: Trailblazer programme works with high school learners to foster noncognitive skills through self-directed social action projects. A retrospective, mixed-method evaluation was completed to assess changes in non-cognitive skills in enke: Trailblazer alumni from 2011 to 2014 and to compare their results across years and social action projects.

Results: Results show that three non-cognitive competencies (grit, growth mindset and selfefficacy) were integral to starting (and finishing) a social action project. Social support, social capital and teamwork were also critical for project success - whilst school location, socioeconomic status and gender were not. Non-cognitive competency development is integral to this programme as there is evidence that building these skills promotes leadership, which creates a bias to action and life-long learning.

Conclusion: This article reflects on the implications of non-cognitive competencies for effective youth development programme design and the youth leadership sector in general.

\section{Introduction}

Young people go to school to increase their knowledge and skills but it takes more than just 'book smarts' to successfully navigate the world outside of school. In addition to academic learning, there are a range of social and emotional skills - non-cognitive competencies - that are necessary for success. These enable people to self-manage and to engage effectively with others. However, even with a growing body of research (Gutman \& Schoon 2013) on what those other skills are, there is not much in the evaluation literature linking research to youth development programmes. As the importance of these skills becomes more evident, the ever-elusive challenge of measuring and understanding whether and how programmes create changes in non-cognitive competencies becomes important.

Youth development is in itself a complex topic. Evaluating it is even more so. Youth development covers everything from youth leadership and formal education to deficit-based models that 'fix' youth. This paper focuses on youth leadership development specifically. Unlike a deficit-based model which focuses on youth problems (Lerner et al. 2006), youth leadership development is the process of increasing the skill sets of young people to a level that allows for positive contribution to the nation - business, academic and social contributions. A big part of that is explicitly building non-cognitive competencies.

enke: Make Your Mark (enke) is a youth leadership development non-governmental organisation (NGO) that incubates youth-led social impact projects, developing the skills of youth to increase their effectiveness as leaders and ability to contribute to a positive future. enke does this by connecting, equipping and inspiring young people to implement social impact projects that tackle issues that affect their communities. This contributes to developing effective young leaders youth who have the desire and capability to access post-school opportunities, whether that is an internship, employment, entrepreneurship or civic leadership.

enke has been running since 2009 and employs specialists in capacitating youth towards social innovation, social cohesion and social responsibility. They have trained over 1700 youth, whose 
projects have had a positive impact on over 25000 people in communities across South Africa. Additionally, through the shared experience of enke's multiple programmes, participants become part of a community of diverse youth who are autonomously working towards achieving better futures for and with each other.

\section{The enke: Trailblazer programme}

With this article we report on the findings of an evaluation of the enke: Trailblazer programme alumni, conducted in 2014. The programme was launched in 2009, runs for 10 months and consists of three components, namely training, support and recognition. The programme inspires, trains and supports high school learners - 'Trailblazers' - from across South Africa to create social impact. Trailblazers from Grades 10 to 12 are nominated by their teachers, and their applications are assessed by enke staff for 'goodness of fit'.

\section{How the programme works}

\section{The Trailblazer programme has three key components:}

Training at the enke: Forum: Participants attend the enke: Forum - a week-long, residential retreat during either summer or winter school holidays. Participants develop leadership, communication and critical thinking skills. They also hear from inspirational speakers and experts in fields such as entrepreneurship, technology, media and the environment. This part of the programme is run primarily by university students who are part of another of enke's leadership programmes.

Social action: Running a community action project (CAP) allows participants to learn by doing (experiential learning). Through this process, participants develop key skills in project design and management. Over the 9-month period, enke provides technical and emotional support for participants through our troubleshooting hotline and monthly SMS reports.

Recognition: We recognise the effort that all participants put into the programme - even where a CAP is not completed. All participants who start a project are invited to regional celebration events. In addition, top projects are awarded prizes and all participants receive a certificate and letter of recognition.

enke's work is an example of providing young people with structured and supported opportunities for learning through experience, outside of the school system. Learners in the last 3 years of high school (Grades 10 to 12) design and run projects to address whichever issues in their community they feel most passionate about. Participants are free to choose whatever project they are inspired to create. These projects are called 'community action projects' (CAPs). enke provides a centralised support function to enable participants to reflect, learn and problem-solve with an enke team member and with each other. This function was introduced in 2011 in response to feedback from participants. The process of running a project is a way for learners to develop leadership skills through supported, self-directed learning. Participants build practical project management skills as well as social and emotional skills such as social awareness, self-efficacy and social responsibility.

\section{South Africa's young leaders}

South African youth face many challenges: an underperforming education system; youth unemployment (currently around 36\%); inadequate infrastructure and service delivery; and violence and substance abuse (Statistics South Africa 2014). Within this context, however, youth leadership development is seen as a potential mechanism for both addressing community-level issues and up-skilling young people enough to successfully contribute to society, now and in future.

Youth leadership development is a way to equip young people to actively contribute to society. In an increasingly complex, interrelated and diverse world, leadership needs to be situational. As such, it is social, it is adaptive and it is relational. This requires a combination of skills - emotional, ethical, practical and cognitive - but particularly skills that foster and build social intelligence and interpersonal relationships (McNeil, Reeder \& Rich 2012).

Whilst youth development organisations vary in the ways they do this, enke puts the emphasis on leadership as action. The organisation believes that leaders - young or old - can only be leaders when they turn an idea into action, inspiring positive social change. In line with the focus on experiential learning, success is indicated by how many participants lead social action projects.

Interventions in youth leadership development are myriad, seeking a range of outcomes. Too often programmes neglect to articulate how and why interventions work, focusing only on if they do. For practitioners in Southern Africa, working across class, educational, geographical and cultural divides poses real challenges. Evaluators and programme designers need more information on what makes youth development programmes work and why. By outlining our assumptions and the mechanisms underlying them, by spelling out the 'intervention theory' (Chen 2006), programme managers can better understand what is happening below the surface. Only by speaking to the leveraging processes can we begin to tailor and strengthen interventions that benefit young people. In this way, we have sought to explore potential mechanisms that are working in the South African context to affect social action with young people.

\section{Leadership and non-cognitive competencies}

Tough (2012) makes a compelling case that children need more than academic skills to succeed. He pulls together both scientific research and the evaluations of several US-based education interventions (e.g. the KIPP charter schools and 
Harlem Children's Zone) to support his hypothesis. He argues that non-cognitive competencies, including persistence, self-control, curiosity, conscientiousness, grit and selfconfidence, are more crucial than sheer brainpower to achieving success. Looking at children at both ends of the socio-economic spectrum, he finds that these skills are not being given the same attention as cognitive skills (the types of skills that are measured by the traditional intelligence quotient (IQ) test or standardised national exams) and yet they are just as important (if not more so). Drawing heavily on the work of Nobel-prize winning economist, James Heckman, he shows that whilst schools are often developing some of these skills as a by-product of their work with young people, more often than not they are not actively prioritising it and are not evaluating their work through this lens (Heckman \& Rubenstein 2001).

Combining and building on work by theorists like Albert Bandura, John Dewey and Lev Vygotsky, there is a recognition that current, mainstream school-education was built to optimise the delivery of education rather than the outcome of learning. Development of individuals often takes place through experience, by allowing a person to learn from role models in the context of observation and doing (Kress 2006). Youth development initiatives contribute to evolving the current education system by providing youth with opportunities to learn from their own direct experience, giving them the chance to drive their own learning and to build more than just the types of skills that end up being tested.

enke's definition of leadership is the ability to take an idea and turn it into reality. This deceptively simple definition was chosen primarily because of its accessibility for the young people who form part of the organisation's programmes. It is based on the definition of youth leadership proposed by The Young Foundation's research: 'young people empowered to inspire and mobilise themselves and others towards a common purpose, in response to personal and/or social issues and challenges, to effect positive change' (Kahn, Hewes \& Ali 2009:6).

However, this definition deliberately entails a number of components that are not necessarily obvious. At its core, this is a definition about non-cognitive competencies. The literature on the topic is inconsistent in its labelling practices (McNeil et al. 2012) - referring to them variously as emotional intelligence, character, social and emotional competencies, and non-cognitive skills. In addition, there is debate over which social and emotional competencies are most important as well as the actual definitions of their content. enke's definition does not present any one competency as being more important than any other, and is built on the assumption that they are interrelated (Dahlberg et al. 2005).

enke's research and evaluation work has focused on three key competencies that are hypothesised to be foundational to youth leadership development in the South African context, as well as having the potential to improve a young person's chances of future success. These three competencies are grit, self-efficacy and a growth mindset.

Grit - Duckworth et al. (2007:1088) define grit as 'working strenuously towards challenges, maintaining effort and interest over years despite failure, adversity and plateaus in progress... The gritty individual approaches achievement as a marathon: his or her advantage is stamina. Whereas disappointment or boredom signal to others that it is time to change trajectory and cut losses, the gritty individual stays the course'. Those with more grit are more likely to overcome obstacles and, in this case, are more likely to complete their CAP.

Self-efficacy as measured by locus of control - Bandura (1994) define this as people's beliefs about their capabilities to produce designated levels of performance that exercise influence over events that affect their lives, primarily as a determinant of motivation (Gutman \& Schoon 2013). Selfefficacy beliefs determine how people feel, think, motivate themselves and behave. However, because self-efficacy is difficult to measure (as noted by Bandura himself), we have chosen to use locus of control as the closest measure. Locus of control is the extent to which individuals believe that they can control events that affect them. Those with an internal locus of control tend to attribute results to their own traits, whereas those with an external locus of control tend to attribute events to external, environmental traits. Those people who exhibit a more internal locus of control are thought to exercise greater levels of self-control (or agency), which may lead to positive life outcomes like less risk-taking behaviour, stronger self-belief and more determination towards own goals.

Growth mindset - Closely linked to self-efficacy and grit, Dweck (2000) argues that there are two types of mindset - a fixed and a growth mindset. In a fixed mindset, people believe their basic qualities, like their intelligence or talent, are simply fixed traits. They spend their time documenting their intelligence or talent instead of developing them. They also believe that talent alone creates success - without effort. In a growth mindset, people believe that their most basic abilities can be developed through dedication and hard work - brains and talent are just the starting point. This view creates a love of learning and a resilience that is essential for great accomplishment, and in our hypothesis, for a greater likelihood of completing a CAP.

Through the Trailblazer programme, enke has been testing a theory of change for high school that includes the three competencies discussed above. The intervention logic is that by equipping high school students with practical project skills, connecting them to role models and expanded social capital, and inspiring them towards action, these young people will develop and exhibit leadership by starting social entrepreneurial activities that positively contribute to their communities. This is based on an assumption that young people can learn, can be 'activated', and want to be integral to social change in their communities. Which is the most 
important part of this logic, and any interrelationships between the parts, need further exploration.

The programme curriculum is based on Kolb's (1984) model of experiential learning. Kolb's experiential learning circle is one of the theories developed as a way of conceptualising how an individual can learn from an experience and use that learning into the future. Experiential learning is a wellrecognised method for reflection and deep learning, and is used by many youth development models - from service learning to internships and outdoor adventure. Few organisations ask young people to start something from scratch, to plan and implement a project with social benefit. These ideas are based on Kolb's model of experiential learning and incorporate the assumptions that (1) people learn best when they have a personal stake in the outcome, (2) personally made discoveries have the biggest effect on learning, and (3) commitment to learning is highest when learners have agency over the objectives within a given timeframe (Ord 2012).

Authors like Tough (2012), Holmlund and Silva (2009) and Roberts (2009) argue that non-cognitive competencies can be developed, either unintentionally during childhood or more intentionally through targeted programmes. Studies have shown that adolescence is a good time to build these, and that there are positive associations between these competencies and 'better' life outcomes. But what do we do to build this as youth leadership organisations? This study examined the results of self-directed, self-motivated action or experiential learning as the operational programme element.

In the process of assessing progress towards stated outcomes, we undertook a small-scale investigation of possible factors affecting change and compared them to our assumptions regarding the causal mechanisms and purported outcomes. We sought to use evaluation to explore how our programme works, for whom and when. We wanted to know if the supposed programme outcomes outlined in our theory of change were true, but also wanted to be able to explain how we achieve the outcomes through facilitating the appropriate ideas and opportunities (Pawson \& Tilley 1997).

Our evaluation sought to answer three questions regarding non-cognitive skills and their impact on a young person's current and future 'success'. In conducting the evaluation, we hoped to gain more insight into which non-cognitive competencies matter and how they are best developed so that our programmes may better foster these competencies in young leaders. With the methodological constraints in mind, the evaluation was designed to be more exploratory than explanatory. The following questions were asked:

- To what extent does 'starting a project' and 'completing a project' impact on key non-cognitive competencies associated with youth leadership (defined as an individual's grit, self-efficacy and growth mindset)?

- What impact does 'starting a project' and 'completing a project' have on graduates' future life path?

- To what extent does support (from enke, family, friends, school etc.) predict participants' likelihood of attempting and/or completing projects (and possibly link to life destination)?

In keeping with a realist evaluation approach, we identified two potential mechanisms for youth action as a result of this evaluation. These are discussed in this article, as well as their application for organisations working in all areas of youth development (education, employment, entrepreneurship and leadership alike):

- Non-cognitive competencies are developed through experiential learning, leading to feedback mechanisms that increase social action success.

- Young people with multiple avenues for meaningful and varied support are better equipped to reach their goals.

Monitoring and evaluation are built into the programme design in order to track progress for the individual and to

Box 1: Community action project examples.

Community action project, Example \#1

School: Rural, Public secondary school

Province: Limpopo

Community action project: Passionate about science, he sought to address the issue of the lack of knowledge of science in his rural community. He started a movement on science awareness targeting every member of his community, especially young people. To do this, he started a science club, raised over R14 000 in funding to support science education at his school and even ran a successful Earth Hour event.

Challenges: 'Raising funds. Attending all my classes and preparing for my common tests while having to make sure that the event wouldn't get out of my hands and not happen.'

CAP status: Complete

Community action project, Example \#2

School: Township, Public secondary school

Province: KwaZulu-Natal

Community action project: Five learners from the same school started the initiative 'Through it all, do it all' to address food and education issues, and give back to the older members of their community. This has resulted in three separate projects being run - a fruit and vegetable garden at the school; a homework club at a community centre; and weekly visits to an old-age home to help residents with chores like washing dishes and cleaning.

At the community centre they assist young people with their homework and motivate them to lead positive lifestyles. With the money they won from enke's Incubator Fund

they have held sessions on positive attitudes and inspiring action for a better community - this included purchasing stationery for the students and providing food at the

they have held sessions on

Over 100 people have benefited from this project so far.

Over 100 people have benefited from this project
Challenges: Time management, team dynamics

CAP status: Ongoing

Community Action Projcet, Example \#3

School: Urban, Private High School

Province: Gauteng

Community Action Project: Fixing up orphanage and squatter camp, providing them with good educational material, food and clothing, and medicine and blankets and toys. Aimed to make a cleaner, safer and more suitable environment.

Challenges: Break-in at the camp, loss of supporter interest, time management with school, finding funding, lack of peer support CAP Status: Started, not finished 
create learning for programme improvement. This article reports on a once-off longitudinal study of alumni, funded by the First Rand Foundation, and conducted by the authors as internal staff members of enke. Whilst this is an internal evaluation, none of the authors were programme coordinators or primary programme implementation staff.

\section{Method}

This was a mixed-method, non-experimental (post-test or observational only) design delivered once in 2014. Owing to a lack of baseline or comparison data, the evaluation questions were best answered with a mix of exploratory methods. Triangulation between samples and methods was achieved through combining survey methods with group interviews, comparison to national data, and the literature where appropriate. The methods were chosen from a rigour, practical and budgetary perspective. With a large and dispersed population - not all of whom had contact details on file - the largest reach method needed to be electronic and as such, a mainly quantitative online survey was designed to increase response rate and reach. Further exploration of answers was best achieved through the use of group interviews in various provinces.

The study was open to all alumni of the enke: Trailblazer programme from 2009 to 2012 (inclusive), a total of 530 people.

\section{Design and analysis}

\section{Survey}

An online survey was created and sent once (in 2014) via multiple online modalities. A R20 incentive was offered for completing the survey. It included a number of questions on demographics, life destination, perceptions of support and descriptions of the participant's CAP. It also utilised three short surveys (built into the main survey) measuring the following non-cognitive skills:

- Grit (adapted from Duckworth \& Quinn 2009)

- Locus of control (adapted from Rotter 1966)

- Growth mindset (adapted from Dweck 2006)

The grit, locus of control and growth mindset instruments were designed and tested by subject-matter experts and have been validated previously (see references above). Analysis of quantitative questions was performed with Microsoft ${ }^{\circledR}$ Excel and JMP 11 software. Qualitative questions were analysed as Microsoft ${ }^{\circledR}$ Word documents. Inductive analysis allowed for interpretation of various themes within the structured questions.

\section{Group interviews}

Group interviews took place in five provinces with graduates from all years and CAP statuses (no stratification by CAP status or year). They were designed to investigate three key concepts from the survey - (1) leadership skills (specifically non-cognitive development), (2) the experience of the CAP process, and (3) support structures utilised and needed. Both convenience and purposeful sampling were used to gather participants for group interviews.

Interview data were captured and stored in NVivo, then analysed through content analysis with themes arising inductively. Major themes were coded, relationships tested and compared against survey findings.

\section{Results and discussion}

Thirty-five per cent of the total alumni population began the survey $(n=185)$ and 159 of those completed it. All data presented are based on those who finished the survey. We have no way of knowing if those who finished the survey are systematically different from those who were able to finish the survey. Our guess is that they were likely doing the survey on their phones and the network dropped - a common problem in South Africa and not based on any systematic difference in class, race, age, gender, province etc.

Demographics are presented in Table 1. The age, gender, province and funding source (whether individuals' participation was sponsored or self-funded) of survey respondents is representative of our general alumni population; however, there is an over-representation of rural respondents.

\section{A mechanism for building non- cognitive competencies: Experiential learning}

Our model is based on the idea that as young people through experiential learning - apply concepts in reality, a number of their capabilities and competencies are built that lead to success in participants' projects. Our data suggest that for grit, growth mindset and locus of control, this may be the case. Whilst the data do not show gender, geography, school or age to be associated with project success, it does not rule out the possibility that these factors (or other mechanisms stills) are important. With an experimental design and random allocation these factors may show themselves to be strong correlates of youth social action success.

\section{Non-cognitive mechanisms: Grit and growth mindset}

We investigated the relationship between three noncognitive competencies and CAP status - from not started

TABLE 1: General demographic breakdown of study participants.

\begin{tabular}{lcc}
\hline Variable & $\begin{array}{c}\text { Survey participants } \\
(\boldsymbol{n}=\mathbf{1 5 9 )}\end{array}$ & $\begin{array}{c}\text { Group interview participants } \\
(\boldsymbol{n}=\mathbf{2 9})\end{array}$ \\
\hline Age (years) & $17-23$ & $17-21$ \\
$\begin{array}{l}\text { Province (\% of total } \\
\text { participants) }\end{array}$ & Gauteng 53\% & Gauteng 30\% \\
& Western Cape 19\% & Limpopo 25\% \\
& Limpopo 14\% & Western Cape 25\% \\
& KwaZulu-Natal 10\% & KwaZulu-Natal 20\% \\
Gender & Female 60\%; Male 40\% & Female 35\%; Male 65\% \\
Rural & $59 \%$ & $34 \%$ \\
Funded & $82 \%$ & $79 \%$ \\
\hline
\end{tabular}


TABLE 2: Mean non-cognitive scores of alumni by CAP status.

\begin{tabular}{lccc}
\hline Non-cognitive skills & Not started & Not finished & Ongoing/Complete \\
\hline $\begin{array}{l}\text { Mean grit (highest score } \\
\text { possible = 5) }\end{array}$ & 3.276 & 3.507 & 3.625 \\
$\begin{array}{l}\text { Mean growth mindset } \\
\text { (highest score possible = 8) }\end{array}$ & 5.071 & 5.411 & 5.512 \\
$\begin{array}{l}\text { Mean locus of control (lower } \\
\text { scores = internal, higher } \\
\text { scores = external) }\end{array}$ & 6 & 5.852 & 5.820 \\
\hline
\end{tabular}

to ongoing/complete (Table 2). Results show a trend of increasing grit and growth mindset amongst people who finish their projects (grit: $r=0.19$, range 1.75-5, median 3.5; growth mindset: $r=0.08$, range $1-8$, median 5$)$. None of the average scores were extreme, suggesting that moderate scoring is enough for achievement in the CAP process, i.e. there is a jump in scores from those who do not start to those starting a project.

Grit is especially important as a mechanism for future success; employers and educators alike attest to the value of young people who are able to bounce back from adversity and remain committed to a goal in the long term. Group interview participants spoke of growing their resilience, persistence, perseverance, patience and their desire for achievement. Whilst none of these are 'grit' exactly, people spoke about these as separate concepts with a common theme. Much of the discussion centred on how people sustain their efforts over the project period and how they continue to motivate themselves after setbacks. Learning 'patience' was a big part of fulfilling their commitments; learning to wait for the right time, right resources and support and not giving-up before they happen.

Duckworth et al. (2007) recognise a link between growth mindset and grit - that having a stronger growth mindset is beneficial to acting with grit - which is also borne-out in our findings (correlation between grit and growth mindset scores $r=0.44$ ). In their stories of hard work, alumni who finished their CAPs show growth mindset to be related to grit by affecting the way people see obstacles as moments of learning rather than defeat, enabling people to adapt their plans to challenges. People spoke of an improved ability to solve problems and carry on as a growth mindset is developed. So whilst we do not know exactly why some people have more grit than others, we can see that building a growth mindset may be a good place to start.

As young leaders, alumni spoke of needing to change the mindsets of community members and their friends (including their team members) about young people's ability to take action. Finding support when many people around you think you cannot was one of the biggest barriers to both starting and finishing a CAP. One of the key leadership lessons centred on understanding your own abilities and knowing that with dedication and hard work you can improve in almost any ability or skill. Having other people in your network who feel the same way could be seen as a mechanism for action.

\section{Locus of control}

We hypothesised that the belief in one's own ability to affect change, your perceived self-efficacy, would be a mechanism for action. This is especially important in young leaders as they learn about themselves, their capabilities and their competencies. Measures of locus of control can act as a proxy measure for self-efficacy - where scores fall on a spectrum from external locus of control (a belief that one has very little control over the world) to internal locus of control (the belief that events are determined and controlled by your own actions and decisions). Survey scores for locus of control were negatively linked to CAP status, meaning there was a weak trend between finishing a CAP and having a more external locus of control, although the differences were small and there is almost no correlation $(r=-0.05$, range $3-8$, median 6$)$.

Finding a trend towards a more external locus of control across CAP groups was surprising but may reflect a change in attitude towards self-efficacy in response to challenging situations (i.e. undertaking a CAP). We predicted that the way people perceive challenges (much like growth mindset) is linked to their sense of self-efficacy and their sense of control in the world around them. As people move through the project and experience a wide range of hurdles, they may become more confident but also more realistic about what in their environment they can or cannot control.

Given the demographics of the cohort (people under 25, life stage, socio-economic status) we can assume that some of these findings might be linked to sample selection bias. This is interesting, because Ozmete (2007) asserts that women, younger people and those from under-resourced areas - which is the majority of our alumni - tend to be more externally located. Such a slight decrease in locus of control score may be explained by a bias in self-report; if alumni never stepped out of their comfort zone (by not starting a project), they might feel more in control by never having tested themselves.

Tella, Tella and Adeniyi (2011) suggest that moderate levels of self-efficacy and locus of control are more important for leadership than extreme levels, as it allows people to be more adaptive to situations. So in essence, we may just be moderating the self-efficacy of participants and in turn building their adaptive leadership competencies. When alumni talk about finding courage and self-confidence, they are moving from thinking about an idea to having the courage to believe in themselves and their ability to achieve their goals - the very essence of self-efficacy. This move from extreme internal locus of control is important for leadership in that one focuses less on control and more on appreciating community and collaboration. This is critically important in the diversity of post-apartheid South Africa, where tackling social issues requires innovative ideas to bridge social and economic inequalities. 


\section{Support mechanisms}

The findings suggest that there are a number of different support mechanisms that allow young people to take action, namely the type of support, the number of support options and team work.

The majority of people needed support to successfully run a project. Even when alumni did not receive support from enke, they found support from others in their communities. Those that finished a project reported higher levels of support from a variety of people and organisations.

In fact, those that finished projects had a higher number of distinct supporters (i.e. school, family, church and friends), so the number of different support options is important too. CAPs that were 'ongoing/complete' utilised an average of four different support options, whereas CAPs that were 'not started' utilised only one. The implication is that, as with most relationships, no one entity can fulfil all your requirements and thus multiple organisations or people who contribute different ideas and resources are necessary in assisting young people to overcome the various challenges presented.

\section{Emotional support}

Results show that support from family and friends is very important for starting and completing a CAP. The biggest difference between 'ongoing/complete' and 'not started' were in having friends ( $82 \%$ had support vs. $43 \%)$ and family (71\% vs. 57\%). People received mostly emotional support from family and friends. Those finishing a CAP had more reported support from their school and enke; those with an 'ongoing/complete' CAP had three times more support from community groups and schools, although the type of practical support was different.

We investigated elements of both emotional and practical support. Our findings suggest that emotional support is most important of the two. This may be necessary for continued support in developing non-cognitive competencies, which are essential for continued progress on projects, as well as self-development whilst at school. It could simply be the lynchpin - if you have emotional support you'll feel better able to find practical support on your own, but without emotional support you'll struggle to keep going even if you have practical project skills and resources.

Emotional support fostered people's motivation and built their confidence - things that are necessary for both grit and internalising a locus of control. Getting people to understand the project and what is to be achieved creates buy-in. As more people come to understand the ideas and motivations, they are more willing to assist and become more involved. This entails practical support in terms of planning, but also emotional support in terms of having someone who believes in you and your ideas. These people often have a way of keeping participants on track and encouraging accountability.

\section{Teamwork}

As seen in Figure 1, nearly $40 \%$ of people who finished a CAP worked in a team, whereas everyone who did not start one worked on their own. It was found that team members provided positive reinforcement of success and boosted confidence. They also helped to solve problems when participants did not know what to do or how to do it, and provided a range of emotional support measures. For example, one interviewee described building competencies through team work: '[you come] to understand that they're different and not everyone you like will be right..., you need to have emotional intelligence to know how to handle people and know how to delegate and not take everything on yourself, because you don't have all the answers'.

Group interview data described a team as useful for implementing a CAP, problem solving and staying motivated even if the project went unfinished. Not having a team was seen as a barrier to completion and sustained effort, which will have implications for programme design. Finding and maintaining inspiration and motivation is essential for the continued pursuit of goals and growth of these skills. The encouragement and inspiration from people on the ground school community, friends and family - was seen as most important.

The main reasons for not finishing a CAP cited in the survey (insufficient time, resources, support from peers) could all be addressed by improved support structures, including having the right people on your team. A possible exception is time, especially for those in their final year of school; however, having an effective team might be beneficial.

Time is a very real problem for some learners, especially those who manage to start their CAP before the end of Grade 11 and cannot continue in their final year. However, those that were successful in their CAPs considered having other people to help them with implementation - even reshaping the project vision - invaluable.

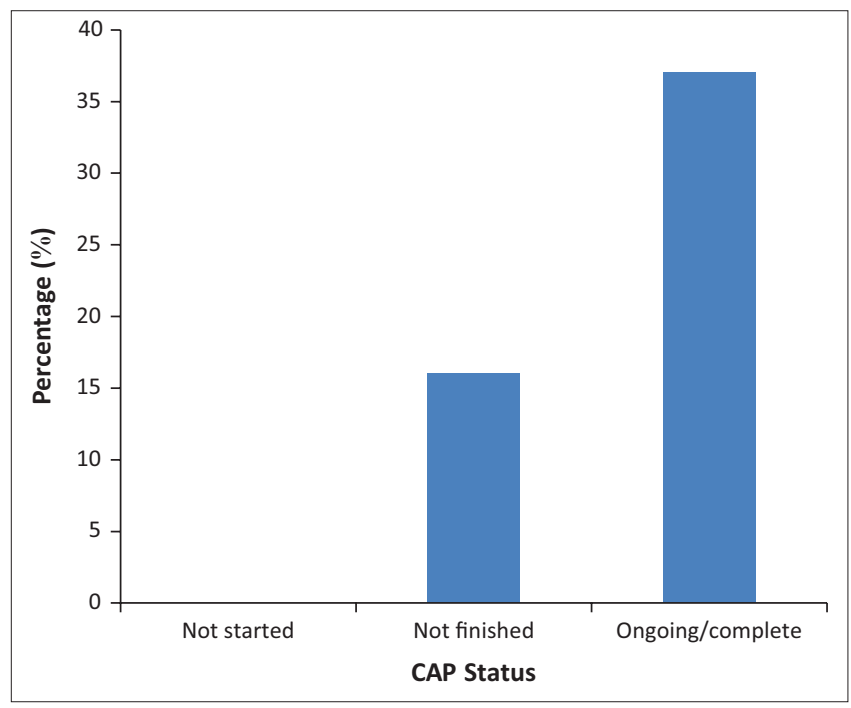

FIGURE 1: Percentage of participants per CAP status that worked in a team. 


\section{What are alumni asking for?}

When examining the conditions for completing a project, we found a difference in the type of support alumni received. Survey and group interview results indicate that even when the different CAP status groups received support from the same people (i.e. teachers, family members), they asked for different things. From family, those in the 'not started' group received motivation, whereas those in the 'ongoing/ complete' group received emotional support (including actions like empathy, deep listening, sharing etc.); from school and community groups, those in the 'not started' group received skills, whilst those in the 'ongoing/complete' group received facilities such as access to classrooms, community halls or sports grounds. These differences show that the 'right' kind of support must be requested or provided in order for that support to be a true value-add. Working with young people to help them identity what kind of support is most needed and where to find it will be important for maximising the add-on effects of social capital and support.

We also saw a difference in the way participants describe the need for support. For example, for those who did not finish a $\mathrm{CAP}$, grit was associated more with not wanting to fail, with trying to find their passion and with having patience with the process. For those who did complete a CAP, grit was closely tied to a deeper need to achieve, combined with a valuedriven respect for persistence which enabled a broader scope of problem solving skills, which in turn allowed them to garner greater buy-in from others and allow them to mobilise more support. This provides further evidence for the link between higher grit scores and persistence and the ability to gain support in those who completed a CAP.

\section{Linking mechanisms}

It is clear from the literature and our study that these mechanisms are interrelated. Whilst our study does not infer causation, we have found that there are some key mechanisms that allow programme participants to achieve success regardless of demographics. What we cannot show is directionality. Authors like Duckworth have shown grit as a stronger predictor of success than IQ or physical competence, but our study was not designed to prove the directionality of causal mechanisms. We simply tried to assess which factors seem to be important and how they relate to each other.

Even when we have ways of measuring concepts like noncognitive competencies, we have very little information on the directionality or dose-response of changes. For example, our sample of alumni may suffer from selection bias so that we are working with young people who already exhibit high levels of grit, growth mindset and self-efficacy. Engaging in leadership training and experiential learning may simply have reinforced what was already present rather than instilled anything - so that those with more developed noncognitive competencies were better able to complete their project.
We also cannot say what small quantitative changes mean. As we continue to measure these mechanisms in our programmes, the literature is unable to tell us what a growth of 0.5 in grit means in the real world. Nor are there recommendations for what the threshold levels are. The average grit score for those who started a project was 3.5, but does a minimum score of 4 on the grit scale predict project completion? Or are we looking for absolute increases (i.e. that any movement towards having more grit is good, regardless of the starting point)?

Support is also a key mechanism for maintaining growth of non-cognitive competencies and project completion. Our question then is, what are the feedback loops between these constructs and how do we find the trigger points to effect development in the right direction?

\section{Limitations}

Whilst 35 per cent is an acceptable sample size, it is small and slightly biased (higher representation of alumni who graduated in 2011 and 2012, and of people who had started and/or finished a CAP). Our recruitment targeted people from earlier years; however, we lacked contact details for many.

Using an online survey with young people in rural and under-resourced areas of South Africa was another limitation. Some were unable to complete the survey online either through lack of phone credit or poor Internet connection. Others were undoubtedly excluded because they were unable to access a computer. We estimate this to be a small number but it cannot be ignored - some $20 \%$ of alumni of 2009-2012 live in a rural area, which limits access to reliable technology. To counter these issues, we offered to conduct the survey over the phone, which only few utilised.

This study was designed to be exploratory rather than explanatory; however, a lack of baseline or other comparison data makes calculating correlation difficult. In many ways we cannot say how strong a link is or in which direction the association runs.

Further research is needed to explore the links between growth in non-cognitive competency development, experiential learning (for example, running a CAP) and life destination. Conducting a comparative or experimental study would also shed light on the strength of association over time since leaving the programme. This research provides a good baseline for following participants over time and test non-cognitive competency endurance and life successes.

\section{Conclusion}

By combining quantitative and qualitative data, we have investigated two mechanisms enabling young people to take social action. Our findings show very little effect of demographic variables (e.g. gender, geographic location, age, 
funding source) and highlight instead the way experiential learning builds non-cognitive competencies, which in turn allow for greater project success. The other mechanism explored was emotional and practical support structures and how they operate on the ground to enhance or hinder social action project success.

In terms of understanding some of the mechanisms that facilitate social action in young people, our biggest lesson was to spur further investigation into how we build community-based support structures. Providing participants with support is important for the process of finishing a CAP as well as personal growth. We have found higher noncognitive competency development in those who finished CAPs and those with more support; fine-tuning programme support is therefore paramount. We have identified the following implications for the Trailblazer programme (and youth development in general):

- Strong relationships with schools can garner increased buy-in and support for learners as schools can play a 'make or break' role in contributing to young people's projects. This support ranges from emotional support and motivation to allowing the use of classroom facilities or other school resources.

- A dispersed model of support that is peer-to-peer led (rather than centralised through enke) and contextually relevant might better meet participants' need for both practical and emotional support, e.g. local alumni can support current Trailblazers through virtual and traditional media or meetings.

- Providing an accountability structure (through organisations and peers) provides motivation for continued effort. Exploring options for strengthening engagement with schools and community groups to encourage a sense of support and accountability will be useful to young people, e.g. through community feedback sessions or dispersing the reporting function.

Even when we can measure changes in non-cognitive skills, the research base is not detailed enough to allow adequate evaluation of the real-world impact of these changes, or to conclusively determine ideal target thresholds. Further research is needed to investigate the interrelated nature of these mechanisms, especially how girt and growth mindset are developed and feed back into each other, and how support mechanisms can be built to further facilitate the growth of non-cognitive skills.

More impact tracking and measurement will be needed to gauge the relationships between different non-cognitive competencies, e.g. which are most important, and to test which other variables are at play. Widening the scope to explore other non-cognitive skills, especially pertaining to social awareness, will further inform programme design. Looking further afield to social capital may shed light on how people mobilise and optimise support.

Youth development organisations are in a prime position to capitalise on the youth of South Africa. Their mission should be to bring about the social benefit accrued from capable, passionate, connected young people with leadership skills who can bring people together for a common goal. Overcoming apathy and negative attitudes to young people's abilities is difficult. That is why supporting young people in their endeavours is paramount. Many of our participants spoke of struggling to secure buy-in and not knowing anyone who had started something before. For young people in more isolated or under-resourced areas, where diversity of and access to opportunities are usually limited, we still found grit, self-efficacy and diverse social support to be effective. Building the knowledge-base will further our understanding on how to empower young people to contribute to the development agenda through self-directed social action.

\section{Acknowledgements Competing interests}

The authors declare that they have no financial or personal relationships which may have inappropriately influenced them in writing this article.

\section{Authors' contribution}

C.W. and P.W. was responsible for the research design. The data collection and analysis was done by C.W. and N.A. Writing and reporting of the article was done by C.W., P.W. and N.A.

\section{References}

Bandura, A., 1994, 'Self-efficacy', in V. Ramachaudran (ed.), Encyclopedia of human behavior 4, pp. 71-81, Academic Press, San Diego, CA, viewed 14 July 2014, from http://www.uky.edu/ eushe2/Bandura/BanEncy.htm

Chen, H., 2006, 'Theory-driven evaluation perspectives on mixed method research', Research in Schools 13(1), 75-83.

Dahlberg, L., Toal, S., Swahn, M. \& Behrens, C., 2005, Measuring violence-related attitudes, behaviors, and influences among youths: A compendium of assessment tools, 2nd edn., Centers for Disease Control and Prevention, National Center for Injury Prevention and Control, Atlanta, GA.

Duckworth, A., Peterson, C., Matthews, M. \& Kelly, D., 2007, 'Grit: Perseverance and passion for long term goals', Journal of Personality and Social Psychology 92(6), 1087-1101. http://dx.doi.org/10.1037/0022-3514.92.6.1087

Duckworth, A. \& Quinn, P., 2009, 'Development and validation of the short grit scale (Grit-S)', Journal of Personality Assessment 91, 166-174. http://dx.doi. org/10.1037/0022-3514.92.6.1087

Dweck, C., 2000, Self theories: Their role in motivation, personality and development, Psychology Press, Philadelphia, PA.

Dweck, C., 2006, 'Test your mindset', viewed 14 July 2014, from http://mindsetonline. com/testyourmindset/step1.php

Gutman, M. \& Schoon, I., 2013, The impact of non-cognitive skills on outcomes for young people, Education Empowerment Foundations, London.

Heckman, J. \& Rubinstein, Y., 2001, 'The importance of non-cognitive skills: Lessons from the GED testing program', American Economic Review 91(2), 145-159. http://dx.doi.org/10.1257/aer.91.2.145

Holmlund, H. \& Silva, O., 2009, 'Targeting non-cognitive skills to improve cognitive outcomes: Evidence from a remedial education intervention', IZA Discussion Paper No. 4476, Forschungsinstitut zur Zukunft der Arbeit / Institute for the Study of Labour, Bonn.

Kahn, L., Hewes, S. \& Ali, R., 2009, Taking the lead: Youth leadership in theory and practice, The Young Foundation, London

Kolb, D.A, 1984, Experiential learning: Experience is the source of learning and development, p. 38, Prentice Hall, Upper Saddle River.

Kress, A, 2006, 'Youth leadership and youth development: Connections and questions', New Directions for Youth Development 109, 45-56. http://dx.doi.org/10.1002/ yd.154

Lerner, R., Lerner, J., Almerigi, J.,Theokas, C., Phelps, E., Naudeau, S. et al., 2006 'Towards a new vision and vocabulary about adolescence: Theoretical, empirical, and applied bases of "Positive Youth Development" perspective', in L. Balter \& C.S Tamis-LeMonda (eds.), Child psychology: A handbook of contemporary issues, Psychology Press/Taylor \& Francis, New York. 
McNeil, B., Reeder, N. \& Rich, J., 2012, A framework of outcomes for young people, The Young Foundation, London.

Ord, J., 2012, 'John Dewey and experiential learning: Developing the theory of youth work', Youth \& Policy 108, 55-72.

Ozmete, E., 2007, 'An evaluation of locus of control as a system related to life management: A case study on youth', World Applied Sciences Journal 2(S), 691-698.

Pawson, R. \& Tilley, N., 1997, Realistic evaluation, Sage, London.

Roberts, Y., 2009, Grit: The skills for success and how they are grown, The Young Foundation, London.
Rotter, J., 1966, 'Generalized expectancies for internal versus external control of reinforcement', Psychological Monographs 80. http://dx.doi.org/10.1037/ h0092976

Statistics South Africa, 2014, 'National and provincial labour market: Youth Q1: 2008 to Q1: 2014', viewed 10 November 2014, from http://beta2.statssa.gov. $\mathrm{za} / \mathrm{p}=2746$

Tella, A., Tella, A. \& Adeniyi, S., 2011, 'Locus of control, interest in schooling and selfefficacy as predictors of academic achievement among junior secondary school students in Osun state, Nigeria', New Horizons in Education 59(1), 25-37.

Tough, P., 2012, How children succeed: Grit, curiosity and the hidden power of character, Houghton Mifflin Harcourt, Boston, MA. 